ARTIGO

DOI: https://doi.org/10.22481/praxis.v14i30.4369

\title{
CARTAS QUE REVELAM A VIDA: HISTÓRIAS DE PROFESSORES INICIANTES DA ZONA RURAL
}

\author{
LETTERS REVEALING LIFE: STORIES OF BEGINNERS TEACHERS IN THE \\ RURAL AREA
}

\section{CARTAS QUE REVELAN LA VIDA: HISTORIAS DE PROFESORES INICIANTES DE LA ZONA RURAL}

\author{
Lúcia Gracia Ferreira \\ Universidade Federal do Recôncavo da Bahia - Brasil
}

Rosa Maria Moraes Anunciato

Universidade Federal de São Carlos - Brasil

\begin{abstract}
Resumo: Este trabalho é oriundo de uma pesquisa de doutoramento que investigou professores rurais em início de carreira e foi realizada a partir da abordagem (auto) biográfica e do método das histórias de vida. O objetivo é analisar aspectos formativos da vida pessoal e profissional revelados em cartas trocadas com os colaboradores da pesquisa por meio de correio convencional, correio eletrônico e através de portadores. As cartas foram trocadas desde o mês de abril de 2011 até o ano de $2012 \mathrm{com}$ dois colaboradores dos municípios de Macarani e Maiquinique, na Bahia. As cartas se constituíram um importante instrumento de produção dos dados e revelaram aspectos inerentes ao contexto rural, tais como: a rotina, a lida na roça, a forma como esses sujeitos aprendem e ensinam, o modo de se relacionar e de socializar seus conhecimentos. O participante narra que já realizou vários trabalhos: atendente de bar, consertou de bicicletas, cortou cabelos, foi entregador de queijos, antes de se dividir entre as atuais funções de mecânico e professor. A participante fala de sua família, das suas dificuldades e descreve uma caminhada longa para a escola, acompanhada apenas do seu cachorro, que referencia como o seu companheiro. Ambos oferecem um panorama da educação rural no sudoeste da Bahia que "grita" por atenção dos responsáveis pela execução das políticas públicas.
\end{abstract}

Palavras-chave: Cartas; Início da carreira docente; Formação.

Abstract: This study is the result of a doctoral research that investigated rural teachers in the beginning of their careers and was carried out from the (auto) biographical approach and the method of life histories. The goal is to analyze formative aspects of personal and professional life revealed in exchanged letters with the research collaborators through conventional mail, electronic mail and carriers. The letters were exchanged from April 2011 to 2012 with two employees from the cities Macarani and Maiquinique in Bahia. The letters were an important instrument for producing data and revealed aspects inherent to the rural context, such as: routine, tasks in the countryside, how these people learn and teach, how to relate and socialize their knowledge. The participant narrates that he has already done several jobs as waiter, bicycle repairs, hair designer, cheese delivery, before being divided between the current functions of mechanic and teacher. The female participant talks about her 
family, her difficulties and describes a long walk to school, followed only by her dog, which she refers to as her companion. Both offer an outlook of rural education in southwestern Bahia that "shouts" at the attention of those responsible for executing public policies.

Keywords: Letters; Beginning of teaching career; Formation.

Resumen: Este trabajo surge de una investigación de doctorado que buscó profesores rurales en inicio de carrera y fue realizada a partir de un abordaje (auto) biográfico y del método de las historias vividas. El objetivo es analizar aspectos formativos de la vida personal y profesional revelados en cartas intercambiadas entre los colaboradores de la investigación por medio del correo convencional, correo electrónico y por medio de portadores. Las cartas fueron intercambiadas desde el mes de abril de 2011 hasta el año 2012 con dos colaboradores de los municipios de Macarani y de Maiquinique, en Bahia. Las cartas se constituyen una importante herramienta de producción de los datos y muestran aspectos inherentes al contexto rural, tales como: la rutina, el manejo de la hacienda, la forma como los sujetos aprenden y enseñan, la manera de relacionarse y de socializar sus conocimientos. El participante cuenta que ya realizó varios trabajos: empleado en un bar, arreglaba bicicletas, peluquero, repartidor de quesos, antes de dividirse entre sus actuales funciones de mecánico y profesor. La participante habla de su familia, de sus dificultades y describe una larga caminada para la escuela, acompañada solamente de su perro, que lo menciona como su compañero. Los dos ofrecen un panorama de educación rural en el sudoeste de Bahia que "grita" por atención de los responsables por la ejecución de las políticas públicas.

Palabras claves: cartas, inicio de carrera docente, formación.

\section{Introdução}

O presente artigo é fruto de uma pesquisa de doutorado desenvolvido a partir do Programa de Pós-Graduação em Educação da Universidade Federal de São Carlos/UFSCar, que analisou o desenvolvimento profissional de professores iniciantes, a partir das narrativas de vida-formação de dois colaboradores sobre trabalho docente no início da carreira em duas escolas rurais nos municípios de Macarani e Maiquinique, situados no Território de Identidade do Médio Sudoeste da Bahia, na mesorregião do Centro-sul baiano, realizada a partir da abordagem (auto) biográfica e do método das histórias de vida.

Foram analisados relatos de histórias de vida e práticas de formação dos participantes por meio das seguintes fontes: questionário (perfil biográfico dos dois colaboradores); cartas; diários e entrevistas narrativas. Para este texto analisamos as cartas trocadas com os participantes que objetivou estabelecer um diálogo contínuo com os professores iniciantes, que propiciasse a compreensão dos dilemas vividos em seus anos iniciais de carreira e como enfrentavam e superavam esses dilemas. Aspectos da vida pessoal e profissional foram 
revelados pelos participantes e também práticas de formação nesse período tão importante da carreira.

A proposta das cartas foi de serem trocadas por um período de um ano letivo, no caso, durante o ano de 2011. Estas foram trocadas através do correio eletrônico e do correio tradicional (convencional), através de portadores.

\section{Por que escrevemos cartas?}

As cartas são instrumentos de cunho social que tem a função da comunicação, de aproximar pessoas ausentes ou distantes, além de estarem ligadas à memória e também ao arquivamento do eu. Segundo Paiva (2006, p.27), se escreve cartas para "conhecer e ser conhecido; para se informar, expressar opiniões e sentimentos, narrar acontecimentos; para alívio próprio, para ser lido por um ou por muitos. Escreve-se, antes de tudo, para conhecer a si mesmo".

Iniciamos destacando dois estudos. Primeiro o de Camargo (2000) e segundo o de Paiva (2006). O primeiro estudo propõe a reflexão da escrita das cartas como prática social, considerando aspectos como pessoa que escreve, para quem escreve, como escreve, quando escreve, o que escreve. Esse tipo de escrita, segundo a autora, deixa marcas, pistas "para uma leitura constitutiva do sujeito da escrita, na escrita" (p. 11). Dessa forma, relata sobre cartas e os seus aspectos históricos, também da carta como objeto de reconstituição da história. Retoma a análise de cartas marcadas pelo tempo, pela história para mostrar como a carta é um objeto de estudo privilegiado, muito mais de indícios do que comprovação, mas que instiga descobertas. Assim, toma as cartas também como objetos ligados as práticas culturais. Nessa perspectiva, as cartas de Agnes Pockels, Euclides da Cunha, Guimarães Rosa e Mario Drummond de Andrade são destacadas. Nesse seu estudo define.

Carta é todo papel, mesmo sem envoltório, com comunicação ou nota atual e pessoal. Considerar-se-á, também, carta, todo objeto de correspondência com endereço, cujo conteúdo só possa ser desvendado por violação. Como sub-itens há a carta-bilhete, carta-resposta comercial, carta-pneumática, cartão postal, cartão-postal comercial etc. (CAMARGO, 2000, p. 50).

A autora ainda fala do surgimento da carta-social, em 1992, que tinha um custo baixo, mas que tinha regras diferenciadas de postagens nas agências dos Correios. A carta estava 
ligada a escrita e ao papel. Nessa perspectiva, desde o final do século passado até o presente século, percebemos mudanças, devido ao uso do computador e do e-mail. Assim,

Carta. Objeto cuja materialidade se traduz nas cores, no apalpar, nas formas, nas letras, e nas múltiplas combinações desses elementos; materialidade que também pode ser um conjunto de folhas avulsas ou conjuntamente dispostas quando impressas num livro; cartas que são textos porque são produções escritas; cartas que são discursos e nelas se buscam significações históricas (CAMARGO, 2000, p. 47).

A autora fala sobre o poder contido nas cartas como objeto do estudo da história, da linguagem e do conhecimento. As diferenças existentes entre estas marcam territórios, contextos e épocas. Baseando-se em Bakhtin, trata a carta como um enunciado, portanto, gênero do discurso - secundário. O trabalho de Camargo prossegue fazendo a análise de 22 cartas trocadas entre duas amigas adolescentes entre 1990 e 1996. Percebe-se nesse estudo, construção para preservar laços de amizades, lembranças, memórias, histórias, distanciamento, saudades, cumplicidade, momentos. Dessa maneira, a autora fala da carta como um veículo que carrega tudo isso.

Paiva (2006), segundo trabalho destacado, relata a história de amizade e sobre cartas enviadas por Mário de Andrade, Carlos Drummond e Cecília Meireles para Henriqueta Lisboa e nos faz uma reflexão sobre as cartas como arquivos da memória e arquivos pessoais. Como memória porque está ligada ao esquecimento, as recordações, as lembranças; porque indica a ausência, a falta. E a carta é uma forma de arquivar a memória; arquivar a vida; fazer a história. A autora aponta dois exemplos, noticiados pela mídia. O primeiro, relacionado a uma urna instalada numa cidade de Goiânia, em 2004, onde os moradores deveriam depositar nela cartas para conhecidos (familiares e amigos) e desconhecidos. Esta urna será aberta somente em 2054, ou seja, 50 anos depois. Assim, a ideia de futuro é marcada através das cartas depositadas que serão também arquivos da memória. O segundo, o fato de uma moradora ter descoberto no interior de uma das paredes de seu imóvel uma garrafa com uma carta dentro, que contava a história da construção daquela casa. Após a leitura, a dona atual do imóvel resolveu escrever outra carta e anexou a esta encontrada e novamente "arquivou" na parede. Os dois exemplos retrataram a carta como instrumento de transmissão e arquivamento da memória.

Outra forma de arquivamento falado pela autora, refere-se a carta como ferramenta de constituição dos arquivos pessoais. Este não se faz sem a memória, mas se configura como 
arquivos pessoais por retratar intimidades, sentimentos, emoções, amizades, fatos, que pertencem a poucas pessoas (a que escreveu a carta e a que recebeu e outras poucas).

Escrever sobre si é uma forma de organizar vivências. Para escrever sobre a vida torna-se necessário abrir o baú de memórias e passar por entre as lembranças. Escrever sobre a própria vida permite ao sujeito que escreve formar-se. A formação também acontece a partir da experiência da escrita, num processo de (auto)formar-se, refletindo sobre si. Dessa forma, nessa perspectiva, as cartas como escrita de si tornam-se também um instrumento formativo. As cartas podem ser papéis carregados de dores, cores, alegria, história, nuances, sentimentos, intimidade, autoria.

Artières (1998, p.11) diz que arquivamos a própria vida quando faz a seguinte reflexão: “Arquivar a própria vida é se pôr no espelho, é contrapor à imagem social a imagem íntima de si próprio, e nesse sentido o arquivamento do eu é uma prática de construção de si mesmo e de resistência". Dessa maneira, conservarmos algumas coisas e outras jogamos fora; e em cada triagem jogamos mais papéis, por exemplo, fora; assim preservamos umas memórias e outras não. As cartas também são papéis muitas vezes guardados, que falam muito de nós.

Não poderíamos deixar de fazer referência ao livro "Papéis Guardados", de Mignot (2003), onde a autora expõe várias figuras dos papéis guardados por estudantes ao longo da vida, sendo fotografias, diários, cadernos escolares, trabalhos escolares, cartas, cadernos de caligrafia, boletim escolar, cadernetas de professores etc. As escritas nesses papéis são como letras que duram, guardadas. Ainda, Mignot e Cunha (2006) referem-se a guardar como:

Guardar é diferente de esconder. Guardar consiste em proteger um bem da corrosão temporal para melhor partilhar; é preservar e tornar vivo o que, pela passagem do tempo, deveria ser consumido, esquecido, destruído, virado lixo. Papéis escritos tidos como "ordinários" tais como cartas, diários, autobiografias, dedicatórias, cadernos de receitas, cartões de felicitações e cartões-postais, até então escondidos dentro de gavetas, armários e caixinhas, "[...] tornam-se presentes como uma voz que nos interpela." (FELGUEIRAS; SOARES, 2004, p. 110). Esses papéis guardam histórias individuais e familiares, trazem marcas da escolarização e permitem pensar distintas interpretações da escola e da educação (p.41).

As cartas podem conservar a vida. Estas guardam muito da vida. Ainda para Camargo (2000a, p. 204): 
Ao se rastrear e analisar o ato de escrever, vão emergindo modos como histórias de escrita são registradas através da escrita das cartas, da correspondência no seu conjunto, do texto, dos procedimentos. Cartas que são datadas e por isso delimitam lugares e momentos particulares na história dos sujeitos e da cultura. Na emergência dessas histórias, sujeitos que escrevem e lêem cartas deixam suas marcas, que podem indicar pistas para uma leitura da constituição do sujeito da escrita, na escrita.

Dessa forma, emergem nas escritas das cartas indícios do processo de formação humana, formação que se dá ao longo da vida, pois enquanto existirmos estaremos sendo formados (FERREIRA, 2010). Emerge nessas escritas indícios da identidade do sujeito, da sua história de vida, da temporalidade (passado-presente-futuro) e das subjetividades.

\section{Cartas trocadas: professores iniciantes da zona rural em evidência}

Nessa perspectiva, iniciamos o trabalho com as cartas no mês de abril de 2011, entregando pessoalmente uma carta-convite as professoras colaboradoras, no município de Macarani; e no final do mesmo mês, foi entregue para os colaboradores no município de Maiquinique. Em Macarani havia duas professoras em início de carreira, das duas recebi carta resposta positiva, aceitando participar da pesquisa; em Maiquinique havia dois professores, desses somente de um recebi resposta da carta. Devido a uma das colaboradoras não ter atendido aos objetivos dessa pesquisa, limitando a missiva a assuntos da vida pessoal e utilizando de evasivas, deixando sem responder a questões ou mesmo mencionar assuntos como a docência, a escola, os dilemas, conflitos, alegrias etc., os dados da mesma não foram analisados. Foi dessa forma que estes se constituíram apenas os dois colaboradores da pesquisa (Cientista de Maiquinique e Matilde de Macarani ${ }^{1}$ ), com quem se dialogou através das cartas e de encontros esporádicos que aconteceram em dias de planejamentos coletivos.

A troca de cartas entre pesquisadoras e colaboradores foi necessária e tida como um objeto adequado devido a distância entre ambos. Buscamos explorar através das cartas as histórias de vida desses sujeitos - história de escolarização, infância, adolescência, vida adulta, momentos e professores marcantes, vida familiar, início da docência, dificuldades em relação à escola entre outros.

Foram enviadas pelas pesquisadoras, entre os anos de 2011-2012, 11 cartas ao colaborador Cientista e oito cartas à colaboradora Matilde. Para Cientista apenas a carta-

${ }^{1}$ Nomes como escolheram ser chamados na pesquisa. 
convite foi entregue pessoalmente, todas as outras foram enviadas por correio eletrônico ${ }^{2}$, por isso, o número de cartas é maior em relação a Matilde. Mas vale ressaltar que por um período (20/07 a 28/10/2011) esse participante ficou sem responder as cartas, mesmo com a insistência da pesquisadora. Ele relatou que nesse período esteve muito atarefado e sem tempo. Quanto a Matilde, esta recebeu pessoalmente a carta-convite e também outras três cartas, as outras quatros foram entregues através de portadores.

A carta-convite era composta de duas páginas e nela havia a apresentação da pesquisa e pesquisadoras e o título e o objetivo de estudo. Nela está uma lista de solicitações feitas, caso a pessoa aceitasse participar da pesquisa. Ao final, propomos aprendermos juntos sobre o processo de formação e (auto)formação, convidando-os para participarem dessa pesquisa. Antecipadamente, agradecemos pela parceria e colaboração e disponibilizamos e-mails e telefones para contato.

O diálogo com os colaboradores iniciou após todos eles terem respondido de maneira positiva a carta-convite. As respostas foram dadas de maneiras diferentes uma da outra. Nas cartas posteriores procuramos cumprimentar os participantes sempre sem muita formalidade, o que possibilitou a aproximação entre os envolvidos. Cumprimentos e comentários sobre a realidade da vida iniciavam as cartas que enviamos a todos. Foi comum durante as cartas a busca de informações sobre a origem, constituição familiar, a infância, a rotina, as dificuldades para chegar até a escola, escola onde lecionava, como chegam a escola, turnos em que trabalhava, situações vivenciadas, como se constituíram professores, se pretendiam permanecer na profissão, a entrada na escola como aluno (a), a idade com a qual começou a estudar, a primeira professora, fatos marcantes desse período da escolarização, período de alfabetização, ensino fundamental e ensino médio, motivos que os levaram a optar pelo magistério, como foi esse período, professores marcantes, realização como professor (a), projetos de vida, desafios. Em todas as cartas nos disponibilizávamos a escutar tudo mais que eles quisessem falar além daquilo que fora perguntado. O diálogo com alguns participantes tomou uma dimensão maior e questões como medo, alegria, tristeza, sonhos, metas, família, frustrações, realizações, certezas, desejos surgiram nas cartas. Assim, abaixo apresentamos os conteúdos das cartas trocadas com os colaboradores da pesquisa.

\footnotetext{
${ }^{2}$ As cartas eram anexadas, sendo o e-mail o suporte deste gênero. Estas cartas digitadas eram escritas com as mesmas formalidades e elementos da carta escrita em papel.
} 
Ao longo do ano de 2011, recebi $^{3} 10$ cartas do professor de Maiquinique (Cientista), pelo correio eletrônico. Essas trocas se iniciaram no mês de maio e encerraram no mês de dezembro de 2011, sendo que enviei uma carta para Cientista no mês de janeiro de 2012. A primeira carta foi uma carta-convite. Na primeira carta que recebi de Cientista, disse apenas sim, aceitando ao convite, no corpo do e-mail. Na segunda, se apresenta, fala de coisas como: sua formação (Magistério do Ensino Médio), que é concursado, que é mecânico durante o dia e professor à noite, sobre a escola onde trabalha, que o grande desafio enfrentado era alfabetizar alunos letrados, sobre o planejamento pedagógico e o apoio administrativo e pedagógico recebido. Também sobre a sua rotina.

Na carta seguinte, Cientista falou de si, da dificuldade encontrada- o concurso público - e da felicidade que sentiu com o resultado. Falou dos sentimentos em estar na profissão e da dificuldade para escrever um diário sobre sua rotina e sobre si. Na quarta carta reafirma essas dificuldades e discorre também sobre sua origem (nasceu na zona rural) e sua constituição familiar. Fala da mãe, do pai, das suas irmãs, das cidades onde morou, das profissões que exerceu, da separação dos pais e do segundo casamento do pai. Relata sobre a esposa: quando a conheceu, do casamento e da mudança para Maiquinique. Recorda algo que gostava de fazer, andar de bicicleta.

Na carta posterior, (quinta) diz novamente que não é fácil falar de si e da facilidade que tem para relacionar-se com o outro. Relata a dificuldade, no começo, de conciliar as duas profissões - mecânico e professor - e novamente da dificuldade para escrever o diário. A sexta carta é iniciada dizendo que pensou muito antes de aceitar participar dessa pesquisa. Fala sobre uma boa recordação da infância, sua avó materna e da paixão por bicicletas, durante a adolescência. Na carta seguinte, enfatiza que foi a mais difícil para responder, certamente, porque a resposta remetia a muitas lembranças, e momentos charneiras ${ }^{4}$. Fala de ter morado na zona rural e vir estudar na cidade e de não ter lembranças dos professores. Também sobre o fato de ter estudado sempre em escolas públicas e a volta da mãe para a Bahia. Que fez Magistério na cidade de Maiquinique e fala sobre isso. Afirma o desejo de cursar o nível superior e a necessidade que já sentiu dessa formação.

\footnotetext{
${ }^{3}$ As cartas foram trocadas entre os colaboradores e a primeira autora, orientada pela segunda autora. Portanto, usaremos aqui a primeira pessoa para dar fidedignidade a ação da forma como ocorreu.

${ }^{4}$ Para Josso (2004, p.64), "momentos ou acontecimentos charneira são aqueles que representam uma passagem entre duas etapas da vida, um 'divisor de águas', poderíamos dizer. Charneira é uma dobradiça, algo que, portanto, faz o papel de uma articulação. Esse termo é utilizado tanto nas obras francesas quanto portuguesas sobre as histórias de vida, para designar os acontecimentos que separam, dividem e articulam as etapas da vida". É um momento marcante.
} 
"Sempre ouvi dizer que ser professor era difícil, isso era desanimador, porém na minha escola isso não ocorre". É dessa forma que inicia a oitava carta. Constata isso, falando de sua turma, seus alunos e sua metodologia em sala de aula. Discursa sobre ser professor e seu retorno, ano posterior, aos estudos. Na carta nove, respondendo a uma pergunta feita numa das cartas anteriores: sobre os professores que mais marcaram sua vida escolar, fala sobre três. Traz a escrita sobre a dificuldade de lecionar numa turma multisseriada. Enfatiza o retorno aos estudos em fevereiro e sua aprovação no vestibular para cursar Educação Física. Deseja-me felicitações natalinas. Na última carta (décima) fala do projeto de entrar para faculdade, sobre seus alunos, o trabalho docente realizado e a gratificação desse trabalho.

Tabela 1: Dados referentes as cartas trocadas com Cientista.

\begin{tabular}{c|l|l|l|l}
\hline Cartas & Enviadas & Como & Recebidas & Como \\
\hline 1 & $30 / 04 / 2011$ & Entregue pessoalmente & $19 / 05 / 2011$ & Correio eletrônico \\
\hline 2 & $20 / 05 / 2011$ & Correio eletrônico & $25 / 05 / 2011$ & Correio eletrônico \\
\hline 3 & $31 / 05 / 2011$ & Correio eletrônico & $01 / 06 / 2011$ & Correio eletrônico \\
\hline 4 & $09 / 06 / 2011$ & Correio eletrônico & $10 / 06 / 2011$ & Correio eletrônico \\
\hline 5 & $25 / 06 / 2011$ & Correio eletrônico & $28 / 06 / 2011$ & Correio eletrônico \\
\hline 6 & $11 / 07 / 2011$ & Correio eletrônico & $19 / 07 / 2011$ & Correio eletrônico \\
\hline 7 & $07 / 08 / 2011$ & Correio eletrônico & $29 / 10 / 2011$ & Correio eletrônico \\
\hline 8 & $19 / 11 / 2011$ & Correio eletrônico & $22 / 11 / 2011$ & Correio eletrônico \\
\hline 9 & $25 / 11 / 2011$ & Correio eletrônico & $03 / 12 / 2011$ & Correio eletrônico \\
\hline 10 & $06 / 12 / 2011$ & Correio eletrônico & $13 / 12 / 2011$ & Correio eletrônico \\
\hline 11 & $31 / 01 / 2012$ & Correio eletrônico & - & \\
\hline
\end{tabular}

Fonte: Dados da pesquisa.

O fato de trocar cartas, pelo correio eletrônico com Cientista proporcionou um número maior de cartas enviadas e recebidas, em relação à outra colaboradora dessa pesquisa. Mas, o número ainda é pequeno, isso porque houve um período, conforme tabela acima, em que Cientista cessou o envio das cartas. Como tinha me enviado um e-mail comunicando que estava com problemas, respeitei esse momento, retomando, dois meses depois à troca de cartas.

De Matilde recebi oito cartas, durante o ano de 2011, todas através de portadores e apenas uma carta no ano de 2012. Assim, na primeira carta, a colaboradora enviou um texto que se chamava "A janela", não disse nem, sim nem não a respeito da participação na pesquisa, mas falou um pouco de si. Entendi isso como um sim. Não comentou o texto enviado. Na segunda carta, Matilde fala do privilégio em participar da pesquisa e comenta o texto enviado, conforme solicitei, esse comentário, vem logo no começo. Fala que o texto enviado é uma reflexão de sua vida, se desabafa e conta coisas íntimas. A carta de Matilde foi 
escrita numa folha de caderno grande, frente e verso. Chamou atenção da pesquisadora o contorno feito de hidrocor preto na frase "prezada amiga" e as flores e folhas desenhadas de ambos os lados. Ela sempre se refere a pesquisadora como "amiga". No conteúdo dessa carta, uma frase "enviei o texto a você por ter me simpatizado com você". Dessa forma, foi se constituindo a relação entre mim e Matilde. Na terceira carta, expressa a confiança depositada sobre a minha pessoa, fala de suas metas (submeter-se e ser aprovada em concurso público), do seu sonho da casa própria e do desejo de ficar perto do seu filho. Diz que está em busca da estabilidade financeira e que pretende continuar lecionando.

$\mathrm{Na}$ carta seguinte, pediu desculpas por não ter respondido as cartas antes. Discorre sobre a decepção de estar com o salário atrasado há dois meses. Reafirma o sonho da casa própria e o esforço que o marido vem fazendo para realizá-lo. Também explica a sua constituição familiar (mãe, pai e três irmãs) e o fato de ter sido abandonada pelo pai. Faz referência às dificuldades que a família enfrentou por conta da ausência do pai, do reaparecimento há sete anos. A aposentadoria da mãe que deverá sair este ano é citada e pedeme para orar por ela.

$\mathrm{Na}$ quinta carta, fala da falta que sente de conversar comigo, pessoalmente; novamente retorna ao sonho de possuir uma casa; narra o seu período de escolarização, lembra da primeira professora e de fatos marcantes. Na sexta carta, fala de como foi bom e proveitoso nosso último encontro e também sobre como se tornou professora. Fala de sua atividade profissional anterior à de professora e de quando teve seu filho. Ela também que ser professora foi uma oportunidade que lhe surgiu, não foi uma opção, mas também fala da sua responsabilidade para exercer a profissão e do seu gosto em exercê-la.

$\mathrm{Na}$ penúltima carta, Matilde pediu desculpas pela demora em responder à minha mensagem e da experiência adquirida no emprego anterior ao de professora. Refere-se ao filho como a melhor realização de sua vida. Ela fala do fracasso (fracasso como perda) como uma lição, pois através dele se aprende e que na vida temos que abdicar de umas coisas para conseguir outras. Sobre o ser professora, diz que é gratificante e que os melhores sentimentos têm sido construídos em torno da relação construída com os alunos. Conclui dizendo que ser professora é uma realização.

$\mathrm{Na}$ última carta, fala que foi aprovada em um concurso para auxiliar administrativo e que estava muito feliz, e remete ao esforço que fez para conseguir isso. Fala sobre o desempenho dos alunos que a surpreendeu, pois nenhum deles foi reprovado. Também rememora uma festa animada de encerramento que fez na escola. Relata sobre uma faxina 
realizada na escola e o esquecimento do diário (autobiográfico) na prateleira desta, destruído por um temporal, e do pouco aproveitamento que teve das escritas, então se prontificou a passar tudo que pôde aproveitar a limpo para entregar-me. Disse que ficou chateada com isso, mas que passou o que pôde aproveitar do diário para outro caderno. Fala de seus 30 anos de idade, completados no dia da escrita da carta (20/02), e da sua gravidez de quatro meses. Termina a carta dizendo que está com saudades e que me tornei uma grande amiga.

Tabela 2: Dados referentes as cartas trocadas com Matilde.

\begin{tabular}{c|l|l|l|l}
\hline Cartas & Enviadas & Como & Recebidas & Como \\
\hline 1 & $08 / 04 / 2011$ & Entregue pessoalmente & $28 / 04 / 2011$ & Portador \\
\hline 2 & $29 / 04 / 2011$ & Entregue pessoalmente & $11 / 05 / 2011$ & Portador \\
\hline 3 & $12 / 05 / 2011$ & Portador & $08 / 06 / 2011$ & Portador \\
\hline 4 & $09 / 06 / 2011$ & Portador & $28 / 07 / 2011$ & Portador \\
\hline 5 & $11 / 08 / 2011$ & Portador & $27 / 08 / 2011$ & Portador \\
\hline 6 & $02 / 09 / 2011$ & Entregue pessoalmente & $07 / 10 / 2011$ & Portador \\
\hline 7 & $09 / 10 / 2011$ & Entregue pessoalmente & $27 / 10 / 2011$ & Portador \\
\hline 8 & $07 / 11 / 2011$ & Portador & $27 / 02 / 2012$ & Portador \\
\hline
\end{tabular}

Fonte: Dados da pesquisa.

As trocas das cartas com Matilde ocorreram lentamente, nos encontramos algumas vezes durante as reuniões de planejamento, já que ela não faltava, assim, algumas cartas eram entregues pessoalmente. Em alguns períodos, os colaboradores dessa pesquisa demoravam mais para responder as cartas enviadas.

As respostas das cartas de cada um proporcionaram perguntas individualizadas em algumas cartas. Cientista sempre foi o mais objetivo, e devido a este exercer a profissão de mecânico durante o dia e de professor durante a noite fez surgir perguntas relacionadas a conciliação das duas profissões, desafios para exercê-las, adaptação a nova rotina. $\mathrm{O}$ fato de ter ingressado no ensino superior também gerou perguntas em torno das expectativas para a entrada no curso de Educação Física e como planejaria a profissão de professor após ingresso.

Matilde sempre foi muito otimista, mesmo contando histórias de dificuldades. Em suas cartas estavam presentes palavras de satisfação em ser professora e ser mãe. Falava dos sonhos de ter uma casa e ser aprovada num concurso público. As cartas revelaram histórias de vida, sentimentos, desafios, frustrações, origem e composição familiar etc.

Cientista $^{5}$, mecânico e professor, com 35 anos de idade, casado, sem filhos, com formação em Magistério, lecionava na Escola Treze de Novembro, em um acampamento, no município de Maiquinique, na Bahia. Morava nessa cidade e, para chegar à escola na zona

\footnotetext{
${ }^{5}$ Informações do ano de 2011.
} 
rural, utilizava seu carro ou sua moto. Era um professor efetivo, aprovado em concurso público municipal, lecionava há menos de um ano em uma classe multisseriada de Jovens e Adultos, no noturno e achava difícil ser professor e escrever cartas e diário.

Já Matilde ${ }^{6}$ era professora há pouco mais de um ano, casada, mãe de apenas um filho, morava "na roça" no município de Macarani, na Bahia, com o marido, enquanto seu filho residia na cidade com a avó. Lecionava na Escola José Soares do Bonfim, que fica na mesma fazenda onde morava, em uma classe multisseriada de Jovens e Adultos, no noturno. Tinha 28 anos de idade e era contratada. Além de lecionar, também ajuda o marido com seus afazeres da roça. Dizia ter afinidade com a profissão de professor, mesmo não tendo formação para ensinar, achava fácil ser professora, escrever cartas e diário.

Então, após a coleta e a análise desses dados, já tendo conhecimento das características dos colaboradores, partimos para a próxima etapa. Através das cartas pudemos promover os diálogos com os professores, explorando aspectos da história de vida. Após a leitura sistemática de todas as cartas, procuramos identificar as temáticas e separá-las para melhor organização da análise interpretativa. No momento seguinte, foi realizada uma terceira leitura dos dados, para uma maior familiarização com os mesmos, através dos quais pudemos então confirmar através das narrativas (auto)biográficas e das práticas de (auto)formação de professores da zona rural nos anos iniciais da carreira docente, que cada ser é singular em sua história. Posteriormente, esses dados foram cruzados entre si, buscando obter maior consistência dos resultados no processo da pesquisa.

Isso foi importante para identificar o poder socializador da atividade biográfica com os sujeitos envolvidos (colaboradores e pesquisadoras), necessária nesse contexto de formação, já que tem uma intenção estritamente formativa. Dessa forma, os dados das narrativas se configuraram como momentos importantes de produção e narração das histórias de vida, como ressalta Moraes (2004, p.169):

Ouvir a história de vida do professor vem se apresentando como uma alternativa, entre outras, para formar o professor. Entretanto, é importante salientar que não é suficiente somente dar voz ao professor: é necessário fazê-Io refletir sobre as nuances que teceram essa formação. É necessário oportunizar momentos nos quais, a partir da reflexão, seja possível enxergar com mais clareza e consciência como ele vem se tornando professor.

\footnotetext{
${ }^{6}$ Informações do ano de 2011.
} 
Os momentos das produções das cartas proporcionaram essa reflexão. A partir desse instrumento, os professores foram estimulados a falar de si, dos seus processos formativos, a socializar as suas escritas, refletir sobre o que estava sendo proposto.

\section{Nas cartas...: histórias de vida-formação dos professores da zona rural}

No estudo privilegiamos a informação biográfica, o que foi colocado pelos professores, por ser esta uma escrita formativa, e foram explorados aspectos ligados aos dilemas profissionais que foram/estavam sendo vivenciados no percurso de vida-formação desses professores iniciantes. Essas cartas configuram-se como textos epistolares e constituíram-se em uma importante fonte de pesquisa por possibilitar o diálogo entre os colaboradores da pesquisa e pesquisadoras, sendo uma fonte que se utiliza das narrativas das experiências de vividas em diferentes fases da vida, espaços e tempos, revelando seu caráter memorístico.

Nesse trabalho, as identidades dos colaboradores foram preservadas, por uma questão ética e também porque, como diz Paiva (2006, p.32) as “cartas são, sem dúvida, um dos documentos que mais envolvem a conflituosa relação entre o público e o privado". Ainda, porque, segundo a Constituição Federal, no inciso XII do artigo $5^{\circ}$ “é inviolável o sigilo da correspondência" (ANGHER, 2005 apud PAIVA, 2006, p.32). Dessa forma, respeitamos o direito do sujeito de não ser identificado.

As histórias de Cientista e Matilde se diferenciam. Conforme Dominicé (2010, p. 88), "as histórias de vida nunca são as mesmas". A do primeiro é marcada por mudanças, viagens, idas e voltas e por uma construção estruturada de família e modos de vida. Já Matilde tem sua vida marcada pelo abandono do pai, as dificuldades dela, da mãe e das irmãs para sobreviverem, o trabalho doméstico remunerado em casa de família.

Cientista, durante a infância morou com o tio um tempo na fazenda. Na adolescência morou com o pai. Vários foram os trabalhos por onde passou: atendente de bar, em uma academia, consertando bicicletas, cortando cabelos, entregador de queijos etc. A curiosidade o despertou para conhecer motos e a desmontá-las e montá-las. O casamento com G., sua esposa, aconteceu em 2007 (Carta 4). Sua melhor recordação é relatada em outra carta.

O que mais me recordo da minha infância é da minha avó paterna. E na minha adolescência a minha paixão por bicicletas (Carta 6 - Cientista). 
Josso (2004, p. 43) aponta que "os contos e as histórias da nossa infância são os primeiros elementos de uma aprendizagem que sinalizam que ser humano é também criar as histórias que simbolizam a nossa compreensão das coisas da vida”. Dessa forma, as lembranças da infância nos permitem aprender. É na infância que nos tornamos aprendizes das coisas da vida, do mundo. É nessa fase da vida que somos inseridos em um processo de aprendizagem que se prolonga durante a vida. Ainda sobre isso Catani e Vincentini (2003, p. 153) dizem que lembramos de algumas coisas e esquecemo-nos de outras, mas ao narrar o sujeito:

[...] sofre a influência do distanciamento temporal que atua em todo processo memorialístico, apagando determinadas experiências e intensificando outras, mas também operam uma seleção, ao escolher os fatos considerados dignos de ser divulgados e ao privilegiar determinados aspectos em detrimento de outros, em busca de dar sentido ao relato da própria vivência.

Assim, tudo que lembramos é importante para nós. A memória nos concede a lembrança, lembrar é viver, é mergulhar numa dimensão temporal. A memória reconstrói, nos possibilita reinventar o passado. Bosi (1983, p. 15), ao se referir a Bergson e sua concepção de lembrança diz que:

A lembrança é a sobrevivência do passado. O passado, conservando-se no espírito de cada ser humano, aflora a consciência na forma de imagenslembrança. A sua imagem pura seria a imagem presente nos sonhos e nos devaneios.

A releitura do passado é realizada através das imagens-lembranças. Na memória estão presentes aspectos das vivências individuais e coletivas, através dos quais o homem também se conhece a si mesmo e à sua história. A memória e a lembrança tomam uma dimensão muito importante na ideia de Bosi, pois para ela:

Não há evocação sem uma inteligência do presente, um homem não sabe o que ele é se não for capaz de sair das determinações atuais. [...] Uma lembrança é diamante bruto que precisa ser lapidada pelo espírito. Sem o trabalho da reflexão e da localização, seria uma imagem fugidia. O sentimento também precisa acompanhá-la para que ela não seja uma repetição do estado antigo, mas uma reaparição (BOSI, 1983, p. 39).

As lembranças se fizeram presentes através das cartas escritas por Matilde e Cientista. Vale ressaltar que para Matilde, o presente e o futuro foram evocados, por meio de uma 
declaração de amor que fez para a sua mãe. Em duas cartas, relata o desejo de criar o filho que passa a semana na cidade com a sua mãe. (Carta 2,3). Traça uma meta, obter aprovação em um concurso público, posteriormente narra que conseguiu alcançar essa meta, foi aprovada para auxiliar administrativo; (Carta 2, 3). Alimenta um sonho, ter uma casa própria (Carta 3, 4, 5). Descreve a surpresa de uma nova gravidez; a destruição do diário da pesquisa, que ocorreu por conta de uma chuva. Essas são narrativas que compõem a última carta (Carta 8). Matilde na carta 2 ainda revela:

Eu não moro na escola como já te falei na outra carta, vou para a escola a pé juntamente com meu cachorro que se chama Hulk, ele é um grande companheiro de todas as horas.

Matilde fala de uma jornada solitária e de uma caminhada longa para a escola, acompanhada apenas do seu cachorro, que referencia como o seu companheiro. Acompanhamos parte da vida pessoal e profissional de Matilde, percebemos que se misturam. A questão emocional também se faz presente, sua relação com um animal de estimação. Aqui o cachorro tem relação com a zona rural, faz parte deste contexto. O cotidiano da prática profissional, leva-a a ser professora e, hoje se constituir como tal.

Assim, essas memórias narradas por Cientista e Matilde revelam suas vidas e indícios de que o ser professor se relaciona com o ser pessoa. Todos esses aspectos da vida desses colaboradores ratificam o que Ciampa (1986, p. 161), afirma:

Não podemos isolar, de um lado, todo um conjunto de elementos (biológicos, psicológicos, sociais, etc.) que podem caracterizar um indivíduo, identificando-o, e, de outro lado, a representação desse indivíduo, como uma espécie de duplicação mental ou simbólica, que expressaria a identidade do mesmo. Isto porque há como que uma interpenetração desses dois aspectos, de tal forma que a individualidade dada já pressupõe um processo anterior de representação, que faz parte da constituição do indivíduo representado.

Diante do exposto, percebemos que o ser é composto por um conjunto de fatores que o constituem, não sendo possível separar o lado pessoal do profissional. Nesse sentido, Matilde e Cientista revelam como as vivências pessoais vão contribuindo na composição profissional. Essa construção do ser professor tem a ver com as escolhas que fazemos, pois "aqueles que se encontrando na profissão, 'são professores' e aqueles que, não se encontrando na profissão, "viram professores"” (FONTANA, 2000, p. 97). A autora refere-se aqui, à condição subjetiva que nos faz professor. As condições objetivas seriam o lugar, as práticas pedagógicas, as 
vivências com os alunos, com os conteúdos, que servem de base para as subjetividades, essa construção subjetiva ligada à identidade que constitui o professor. Dessa forma, somos formados por meio das escolhas que fazemos, nos constituímos a partir delas. As opções da vida pessoal influenciam na vida profissional, como afirma a autora, "O que começa com a escolha feita, se ela, por sua vez, nasce de outras escolhas, de determinações e até de acasos? Não passa por aí a história que cada um de nós ‘é’?” (p. 82).

Sobre essa constituição, Cientista revela que se divide durante o exercício de duas profissões, ser mecânico durante o dia e professor à noite. Duas atividades totalmente diferentes compõem a história de vida desse homem, o tempo (diurno/noturno) também o divide entre uma atividade e outra. Alterna o seu tempo entre o trabalho manual e o trabalho intelectual. $\mathrm{Na}$ dimensão temporal do presente e futuro, desejava e sentia necessidade de ingressar em uma faculdade para obtenção de um curso superior (Carta 7). A decisão de retomar os estudos no ano de 2012 é relatada na carta 8. E a notícia sobre a aprovação no vestibular para o curso de Educação Física é narrada e junto, o desejo também de, no ano de 2012, lecionar essa disciplina (Carta 9).

As ponderações aqui contidas sobre as cartas, os dizeres, as reflexões, revelações, as conversas mostram escritas diferenciadas, marcas de tempos e espaços diferentes. Conforme Bastos, Cunha e Mignot (2002, p. 9), “a escrita epistolar, com múltiplos destinos, transforma a ausência em presença e o passado, em presente, impedindo o esquecimento. Enfim, laços de papel". Esses são os laços de papel que compõem um trabalho que demarca parte da vida de dois professores rurais; papéis que guardam pedaços da vida.

\section{Considerações finais}

A escrita epistolar de professores rurais em início de carreira, tem uma grande importância pelas narrativas contidas nas cartas trocadas entre pesquisadores e professores. Essas escritas são reveladoras da vida e merecem atenção. Foram utilizadas com o objetivo de estabelecer um diálogo contínuo com os professores iniciantes, que propiciasse a compreensão dos dilemas vividos em seus anos iniciais de carreira e como enfrentam e superam esses dilemas. A análise mostrou que mais do que um instrumento para discussão dos aspectos de sala de aula, forneceram um panorama da vida de professores de escolas rurais no sudoeste da Bahia em que muitos problemas presentes na área rural permanecem os 
mesmos ao longo do tempo: precariedade de transporte, prédios sem manutenção sujeito a inundações, atrasos nos salários, falta de formação docente, etc.

As cartas assumem o papel de veículo de denúncia dessas condições e escancaram o lugar ocupado pela educação dessas populações como não prioritários para as políticas.

A invisibilidade social de professores da zona rural foi mostrada nas narrativas desses professores iniciantes que descreveram aspectos inerentes ao contexto rural e seu "silenciamento" foi exposto, salientando que muitas políticas públicas de atendimento a essa população ainda não saíram do papel, nem a lembrança da existência desses sujeitos pode ser percebida, através de ações governamentais.

\section{REFERÊNCIAS}

ARTIÈRES, Philippe. Arquivar a própria vida. Estudos históricos, Rio de Janeiro, v. 11, n. 21, p. 9-34, 1998.

BASTOS, Maria Helena Camara; CUNHA, Maria Teresa Santos; MIGNOT, Ana Chrystina Venancio. Laços de Papel. In: BASTOS, Maria Helena Camara; CUNHA, Maria Teresa Santos; MIGNOT, Ana Chrystina Venancio (Org.). Destino das letras: história, educação e escrita epistolar. Passo Fundo: UPF, 2002. p. 5-9.

BOSI, Ecléa. Memória e sociedade: lembranças de velhos. São Paulo: T. A. Queiroz, 1983.

CAMARGO, Maria Rosa Rodrigues Martins de. Cartas e escrita. Tese (Doutorado). Programa de Pós-Graduação em Educação. Universidade Estadual de Campinas. São Paulo. 2000.

CAMARGO, Maria Rosa Rodrigues Martins de. Cartas adolescentes. Uma leitura e modos de ser... In: MIGNOT, Ana Chrystina Venancio; BASTOS, Maria Helena Camara; CUNHA, Maria Teresa Santos (Org.). Refúgios do eu: educação, história, escrita autobiográfica. Florianópolis: Mulheres, 2000a. p. 203-228.

CATANI, Denice Barbara; VICENTINI, Paula Perin. "Minha vida daria um romance": lembranças e esquecimentos, trabalho e profissão nas autobiografias de professoras. In: MIGNOT, Ana Chrystina Venâncio; CUNHA, Maria Teresa Santos (orgs.). Práticas de memória docente. São Paulo: Cortez, 2003. p. 149-166.

CIAMPA, Antonio. Identidade. In: LANE, Silvia; CODO, Wanderley. (Orgs.). Psicologia social: o homem em movimento. 4 ed. São Paulo: Brasiliense, 1986.

DOMINICÉ, Pierre. O processo de formação e alguns dos seus componentes relacionais. In: NÓVOA, Antonio; FINGER, Matthias. O método (auto)biográfico e a formação. Natal, RN: EDUFRN; São Paulo: Paulus, 2010. p. 81-95. 
FERREIRA, Lúcia Gracia. Professoras da zona rural: formação identidade, saberes e práticas. Dissertação (Mestrado). Programa de Pós-Graduação em Educação e Contemporaneidade. Universidade do Estado da Bahia: Salvador, 2010.

FONTANA, Roseli Aparecida Cação. Como nos tornamos professoras? Belo Horizonte: Autêntica, 2000.

JOSSO, Marie Christine. Experiência de vida e formação. Trad. José Cláudio e Júlia Ferreira. São Paulo: Cortez, 2004.

MIGNOT, Ana Chrystina Venancio. Papéis guardados. Rio de Janeiro: UERJ, Rede Sirius, 2003.

MIGNOT, Ana Chrystina Venancio; CUNHA, Maria Teresa Santos. Razões para guardar: a escrita ordinária em arquivos de professores/as. Revista Educação em Questão, Natal, v. 25, n. 11, p. 40-61, jan./abr. 2006.

MORAES, Ana Alcídia de Araújo. Histórias de vida e autoformação de professores: alternativa de investigação do trabalho docente. Pro-Posições, v. 15, n. 2 (44), maio/ago. 2004.p.165-173.

PAIVA, Kelen Benfenatti. Histórias de vida e amizade: as cartas de Mário, Drummond e Cecília para Henriqueta Lisboa. Dissertação (Mestrado). Programa de Pós-Graduação em Letras: Universidade Federal de Minas Gerais, 2006.

\section{SOBRE AS AUTORAS}

\section{Lúcia Gracia Ferreira}

Doutora em Educação pela Universidade Federal de São Carlos (UFSCar). Professora Adjunta da Universidade Federal do Recôncavo da Bahia (UFRB)/Centro de Formação de Professores. Professora Permanente do Programa de Pós-Graduação e Educação da Universidade Federal da Bahia (UFBA). Pós-doutorado em Educação pela Universidade Federal da Bahia. Pós-doutorado em Letras pela Universidade Estadual do Sudoeste da Bahia. Líder dos Grupos de Pesquisa/CNPq: Docência, Currículo e Formação (DOCFORM) Centro de Pesquisa e Estudos Pedagógicos (CEPEP). E-mail: luciagferreira@ufrb.edu.br

\section{Rosa Maria Moraes Anunciato}

Doutora em Educação pela Universidade Federal de São Carlos (UFSCar).Professora Associada da Universidade Federal de São Carlos (UFSCar); Docente credenciada no Programa de Pós-Graduação em Educação; Grupo de Pesquisa "Estudos sobre a Docência: Teorias e Práticas"; Bolsista de Produtividade nível 2. E-mail: rosa@ufscar.br 